\title{
Anodic deposition of compact, freely-standing or microporous polypyrrole films from aqueous methanesulphonic acid
}

\author{
V. Caramia ${ }^{1,2}$, C. Ponce de Leon ${ }^{1}$, C. T. J. Low ${ }^{3}$ and F. C. Walsh*1
}

Freely-standing and flexible films (0.075 to $9 \mu \mathrm{m}$ in thickness) of electrically conducting polypyrrole were synthesised via anodic electrodeposition onto a stainless steel substrate from methanesulphonic acid under stirred conditions at $295 \mathrm{~K}$. Cyclic voltammetry was used to study the effect of pyrrole monomer concentration ( 0.01 to $\left.1.0 \mathrm{~mol} \mathrm{dm}^{-3}\right)$ and methanesulphonic acid level ( 1.0 to $6.0 \mathrm{~mol} \mathrm{dm}^{-3}$ ) on the formation of polypyrrole films. The films were prepared for deposition times of $30-240 \mathrm{~s}$ at constant current densities of 1 to $15 \mathrm{~mA} \mathrm{~cm}^{-2}$. The ionic conductivity of freely-standing polypyrrole membranes in aqueous methanesulphonic acid was studied. Scanning electron microscopy was used to image the surface microstructure. The polypyrrole films, which were prepared in the oxidised (methanesulphonate doped), conductive state, showed an ionic area resistance as low as $10 \mathrm{ohm} \mathrm{cm}^{2}$. The films were readily doped with the methanesulphonate anion and the membrane ionic conductivity was dependent on the electrolyte composition used for their deposition. In the presence of anodic oxygen evolution, the films showed a 'template-free' porosity due to film growth around the bubbles.

Keywords: Conducting polymer, Methanesulphonic acid, Microporosity, Polypyrrole, Templating

\section{Introduction}

Over the last 40 years, electrochemically synthesised polymers, such as polypyrrole, have become established as an important class of conductive coatings. ${ }^{1-7}$ Electrically conducting polypyrrole films can be synthesised from aqueous or organic solvents by chemical and electrochemical methods. ${ }^{1-7}$ Proposed applications of these films include fields as diverse as: production of elastic textile composites with high electrical conductivity, ${ }^{8}$ supercapacitors for energy storage and secondary batteries using an array of aligned multi-walled nanotubes, coated with conductive polymer composites, ${ }^{9}$ improvement of the shear strength and toughness of graphite fibres ${ }^{10}$ and the ability to electrically switch between oxidised and reduced states leading to a highly conducting or an insulating polymer. ${ }^{11}$ Deposition onto a polished metal substrate results in noticeable differences between the smooth, substrate side and the rougher, solution side of the detached film. Electrochemical synthesis of conducting polymers offers many advantages over chemical synthesis, including the

\footnotetext{
${ }^{1}$ Electrochemical Engineering Laboratory, National Centre for Advanced Tribology, School of Engineering Sciences, University of Southampton, Highfield, Southampton SO17 1BJ, UK

${ }^{2}$ Facoltà di Ingegneria Industriale, Università del Salento, Cittadella della Ricerca S.S. 7 Brindisi-Taranto, 72100, Brindisi, Italy

${ }^{3}$ WMG Centre, School of Engineering, University of Warwick, Coventry CV4 7AL, UK

*Corresponding author, email electro@chemeng.fsnet.co.uk
}

in-situ deposition of the polymer at the electrode surface, hence ability to be processed and control of the thickness, morphology and degree of polymer doping by control of the quantity of electrical charge passed. ${ }^{1-7}$

The electrochemical route to polymerisation is often favoured due to its control and ability to produce compact polypyrrole films by direct anodic oxidation of the pyrrole monomer

$$
\text { Pyrrole }-n \mathrm{e}^{-}+x \mathrm{CH}_{3} \mathrm{SO}_{3}{ }^{-}=\text {doped polypyrrole }
$$

in the presence of an anionic counter ion and dopant, such as an alkylsulphonate. It is well-accepted that the polymerisation takes place via a pyrrole radical cation intermediate and the methanesulphonate counter ion maintains charge balance within the polyprrole (Fig. 1). ${ }^{1,2}$

Polypyrrole films produced in organic solvents tend to have improved coating properties compared to aqueous electrolytes but the solvents can be toxic, highly flammable and expensive. An aqueous solution is much more practical to scale-up production and maintain low costs but can produce powdery polypyrrole having a limited coating lifetime. One method to improve the coating properties involves the synthesis of polypyrrole films in the presence of a conductive salt. The anions of the conductive salt can be directly doped into the polypyrrole films during polymerisation, producing a thick, robust and stable coating.

For some applications, the films must be sufficiently robust to be readily removable from the substrate for further processing. ${ }^{1}$ This severely limits the choice of 
$\mathrm{n}$<smiles></smiles>

(a)

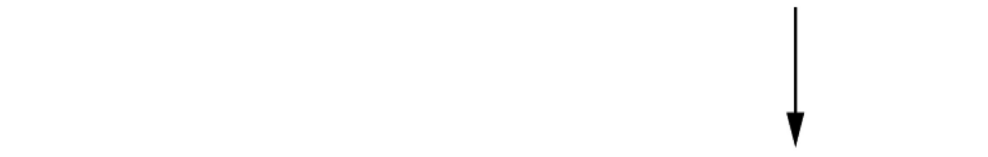<smiles>[3H]n1c(C[Te])ccc1-c1ccc(-c2ccc(-c3ccc(C)n3C)[nH]2)[nH]1</smiles>
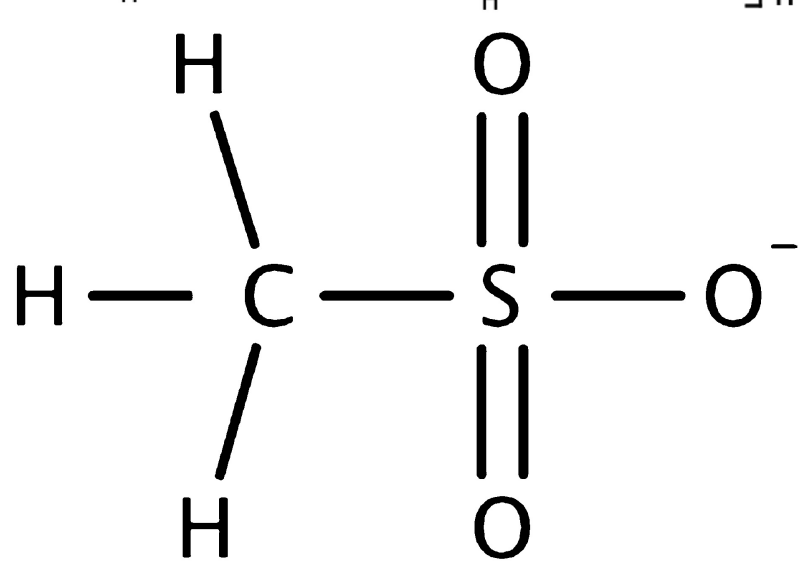

1 Schematic showing a anodic oxidation of pyrrole at inert anode to form staggered, $\pi$-delocalised electron backbone of polypyrrole in $n$-electron change via radical cation intermediate in presence of $b$ methanesulphonate counter ion, $\mathrm{CH}_{3} \mathrm{SO}_{3}{ }^{-}$is used to balance electrical charge within polypyrrole film

electrolyte and operating conditions; the majority of studies concern thin films adhering to a metal electrode. ${ }^{2}$ Recent activities have increasingly focused on the preparation of polypyrrole films from more environmentally acceptable aqueous electrolytes such as methanesulphonic acid. This non-oxidising organic acid has an electrolytic conductivity comparable to sulphuric acid but is less corrosive and biodegradable. ${ }^{12}$ The acid has been used as a green electrolyte in the surface finishing industry and in flow batteries. Examples include cathodic deposition of metals, ${ }^{13}$ alloys, ${ }^{14}$ anodising of lightweight metals ${ }^{11}$ anodic deposition of metal oxides ${ }^{15}$ and anodic oxidation of environmental organic contaminants. ${ }^{16}$

Here, we report the anodic electrodeposition of polypyrrole from methanesulphonic acid and show that the methanesulphonate anions could be directly doped into the polypyrrole during polymerisation leading to a conductive, oxidised film. Other sulphonate anions such as benzene-sulphonate, dodecyl-sulphonate, styrenesulphonate, vinyl-sulphonate and p-toluene-sulphonate are well-known dopants. ${ }^{8,17}$ Such anions have typically been incorporated into polypyrrole films following polymerisation. These films have been synthesised at low current density over a long deposition time to form a stable, non-dendritic coating.
Polypyrrole films are characterised by measurement of surface microstructure, cyclic voltammetry of pyrrole and membrane ionic conductivity in methanesulphonic acid. The effects of monomer concentration, methanesulphonic acid level, deposition time and applied current density on the formation of polypyrrole films are investigated here. These films can be prepared at high current density in the doped and conductive state. Freely-standing, flexible thick films can be readily deposited while controlled porosity films are possible via deliberate oxygen evolution templating.

\section{Experimental details}

\section{Chemicals}

The electrolytes contained 0.01 to $1.0 \mathrm{~mol} \mathrm{dm}^{-3}$ pyrrole monomer in 1.0 to $6.0 \mathrm{~mol} \mathrm{dm}{ }^{-3}$ methanesulphonic acid. All chemicals were analytical reagent grade from Sigma Aldrich UK.

\section{Cyclic voltammetry}

Cyclic voltammetry was performed in a glass, single compartment, three-electrode glass cell of $20 \mathrm{~cm}^{3}$ volume. The electrolyte temperature was maintained at $295 \pm 2 \mathrm{~K}$. The working electrode was a stainless steel plate (SS430, 

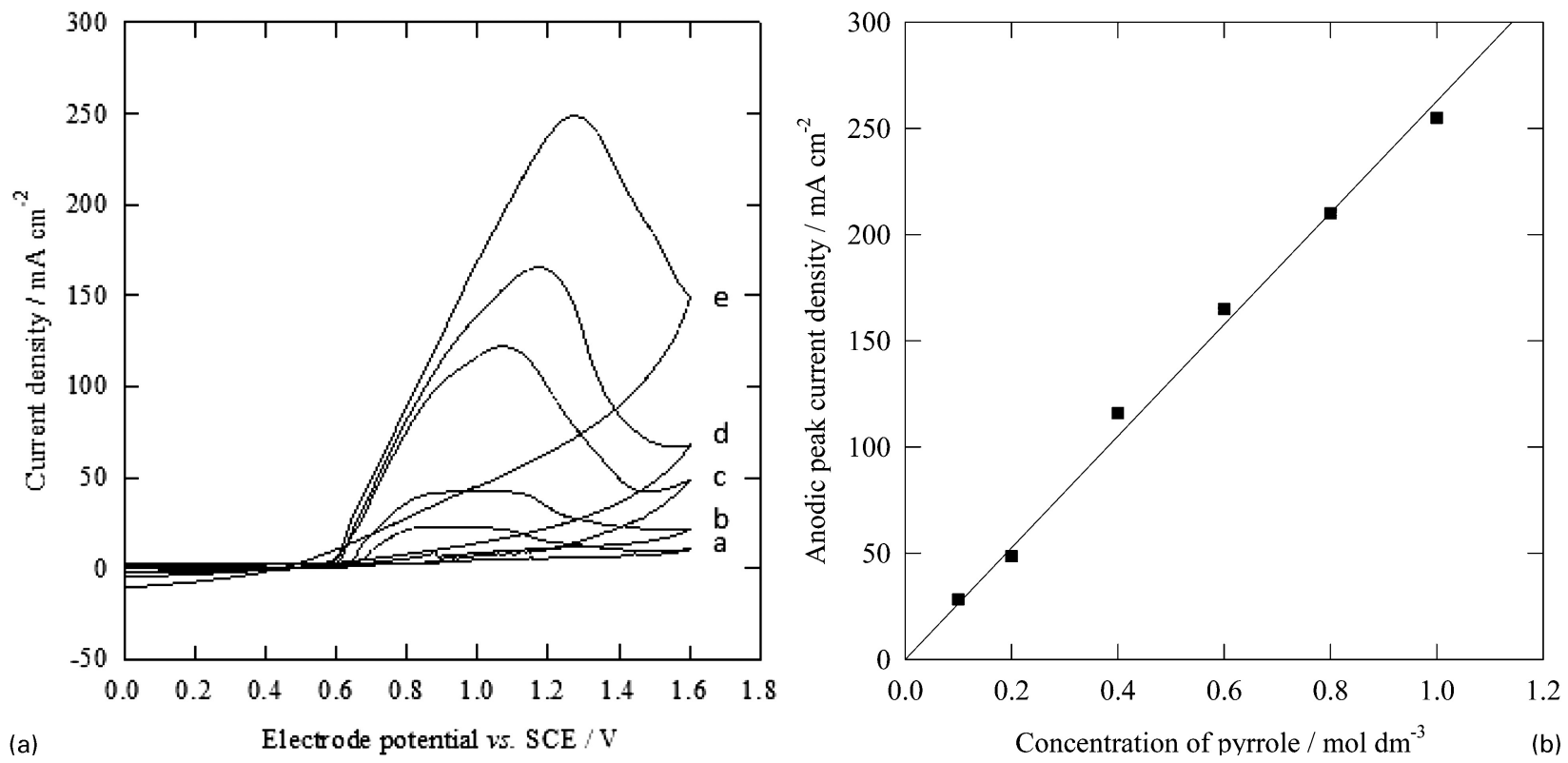

(A) cyclic voltammetry of pyrrole/polypyrrole recorded on stainless steel in different pyrrole concentrations in $0.5 \mathrm{~mol} \mathrm{dm}^{-3}$ methanesulphonic acid at $295 \mathrm{~K}$. Concentration of pyrrole: (a) $0.2 \mathrm{~mol} \mathrm{dm}^{-3}$; (b) $0.4 \mathrm{~mol} \mathrm{dm}^{-3}$; (c) $0.6 \mathrm{~mol} \mathrm{dm}^{-3}$; (d) $0.8 \mathrm{~mol} \mathrm{dm}^{-3}$ and (e) $1.0 \mathrm{~mol} \mathrm{dm}^{-3}$. Electrode potential was linearly swept from 0 to $+1.6 \mathrm{~V}$ (SCE) at $10 \mathrm{mV} \mathrm{s}^{-1}$. (B) anodic peak current density versus pyrrole concentration

2 Effect of pyrrole concentration on anodic deposition of polypyrrole

18/8, Corus GmbH, Germany; area: $\left.1.31 \mathrm{~cm}^{2}\right)$. The counter electrode was a platinum wire (Goodfellow, $\mathrm{UK}$; area: $0.61 \mathrm{~cm}^{2}$ ). Stainless steel plate was a mirrorfinished surface and both electrodes were used in the 'asreceived' condition. The reference electrode was a saturated calomel electrode $\left(3.5 \mathrm{~mol} \mathrm{dm}^{-3} \mathrm{KCl}\right)$. The electrode potential was linearly swept from 0 to $+1.6 \mathrm{~V}(\mathrm{SCE})$ at $16 \mathrm{mV} \mathrm{s}^{-1}$ via a computer controlled potentiostat (EcoChemie Autolab, PGSTAT20) using the General Purpose, Electrochemical Software Version 4.5.

\section{Constant current deposition}

An undivided, beaker cell (volume: $100 \mathrm{~cm}^{3}$ ) was used for constant current anodic deposition of polypyrrole films. The working and counter electrodes (length: $4 \mathrm{~cm}$, width: $5 \mathrm{~cm}$, area: $20 \mathrm{~cm}^{2}$ ) were stainless steel plates (SS430, 18/ 8 , Corus GmbH, Germany). The electrodes were used in the 'as-received' condition. They were placed parallel and $4.0 \mathrm{~cm}$ apart. A PTFE-coated steel magnetic stirrer bar was used to generate flow in the condition at approximately 500 rev $\min ^{-1}$ (Fisher Scientific UK, dimension: $4.5 \mathrm{~cm}$ diameter, $0.8 \mathrm{~cm}$ length). The current was provided using an external power supply (QL355T, Thurlby Thandar Instruments, UK). The electrolyte temperature was maintained at $295 \pm 2 \mathrm{~K}$.

\section{Membrane ionic conductivity}

Ionic conductivity of a freely-standing membrane was measured using a four-electrode, glass electrochemical cell similar in design to that described elsewhere. ${ }^{18}$ To form a freely-standing membrane, four sides of the deposited film on the stainless steel plate were cut using a scalpel. The membrane was readily peeled-off the plate. The ionic current was passed through a circular, $1.3 \mathrm{~cm}^{2}$ polypyrrole membrane via platinum mesh electrodes (Goodfellow, UK; area: $2.0 \mathrm{~cm}^{2}$ ), $12.5 \mathrm{~cm}$ apart. The electrolyte was $1.0 \mathrm{~mol} \mathrm{dm}^{-3}$ methanesulphonic acid each side of the membrane at $295 \pm 2 \mathrm{~K}$. The current applied between two platinum electrodes was linearly swept and the potential difference across the membrane was measured using two identical, saturated calomel reference electrodes (Radiometer Analytical, UK, $\left.3.5 \mathrm{~mol} \mathrm{dm}^{-3} \mathrm{KCl}\right)$. All membranes were used immediately. Electrochemical measurements were made via a computer controlled potentiostat (EcoChemie Autolab, PGSTAT20) using the General Purpose, Electrochemical Software Version 4.5.

\section{Surface microstructural analysis}

The surface microstructure of the membranes was imaged using high resolution scanning electron microscopy (JEOL, JSM 6500F). An accelerating voltage of $10 \mathrm{kV}$ was used and the imaging was carried out with a working distance of $10 \mathrm{~mm}$. The polypyrrole membranes were dried in a vacuum chamber using argon gas for $10 \mathrm{~min}$ before surface microstructural analysis. Samples for SEM imaging were mounted in aluminium stubs using an electrically conductive silver dag and examined in the uncoated state.

\section{Results and discussion}

\section{Substrate materials for deposition of freely- standing polypyrrole film}

During preliminary experiments, various carbon and metal substrates were evaluated as the substrate for the anodic deposition of polypyrrole. The challenges in finding a suitable electrode material were (i) the substrate had to remain stable and not dissolve or oxidise during polypyrrole deposition and (ii) the polypyrrole film could be readily detached from the substrate to form a freely-standing membrane. Aluminium, carbon-polymer, graphite, nickel and titanium were considered but the general appearance and quality of polypyrrole films deposited onto these substrates were poor, despite surface polishing. 


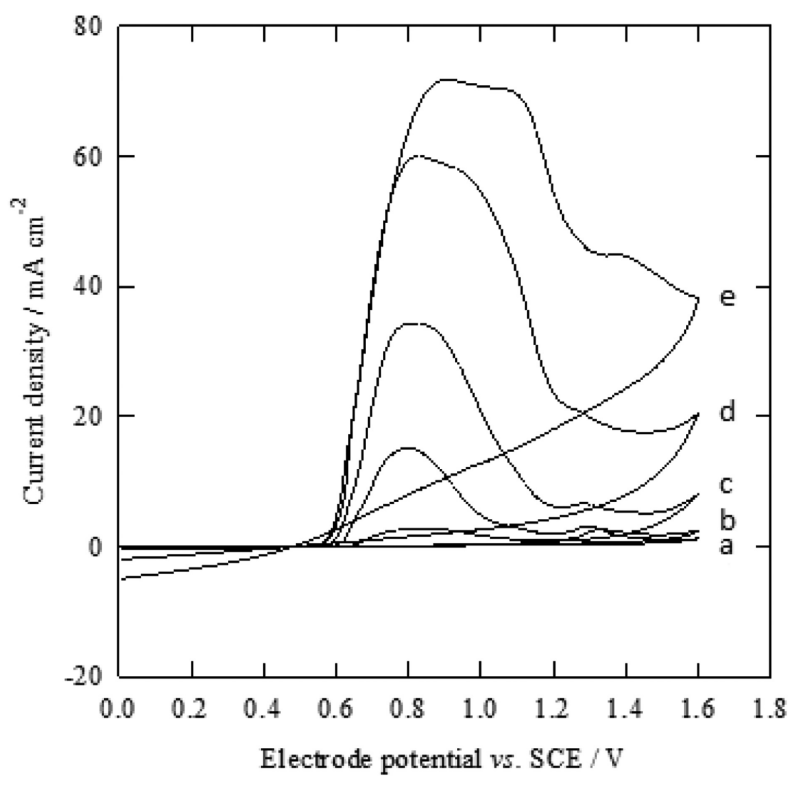

3 Effect of methanesulphonic acid concentration on anodic deposition of polypyrrole. Cyclic voltammetry of pyrrole/ polypyrrole recorded on stainless steel in different methanesulphonic acid concentration in $0.2 \mathrm{~mol} \mathrm{dm}^{-3}$ pyrrole at $295 \mathrm{~K}$. Electrode potential was linearly swept from 0 to $+1.6 \mathrm{~V}$ (SCE) at $10 \mathrm{mV} \mathrm{s}$

An AISI grade 430 stainless steel substrate readily allowed the deposition of good quality polymer films. This substrate had a mirror-finish and polypyrrole readily nucleated on its surface. The polypyrrole films could be grown up to a thickness of several millimetres. The magnitude of electrolyte stirring was crucial to form a compact film. Adequate stirring facilitated detachment of oxygen bubbles from the surface of the growing film which formed due to water oxidation at higher current density

$$
2 \mathrm{H}_{2} \mathrm{O}-4 \mathrm{e}^{-} \rightarrow \mathrm{O}_{2}+4 \mathrm{H}^{+} E=1.229 \mathrm{~V}(\mathrm{SHE})
$$

Under static electrolyte conditions and at a potential sufficiently positive for pyrrole oxidation (above $+1.3 \mathrm{~V}(\mathrm{SCE})$ ) the polypyrrole was found to grow around attached oxygen bubbles to form a highly porous, electrolyte-filled, three-dimensional deposit in a random templating.

\section{Cyclic voltammetry of pyrrole oxidation}

Figure $2 a$ shows cyclic voltammograms for pyrrole oxidation to polypyrrole recorded in an electrolyte containing $0.2-1 \mathrm{~mol} \mathrm{dm}^{-3}$ pyrrole and $0.5 \mathrm{~mol} \mathrm{dm}^{-3}$ methanesulphonic acid at $295 \pm 2 \mathrm{~K}$. At an electrode potential more positive than $+0.6 \mathrm{~V}(\mathrm{SCE})$, the anodic deposition of polypyrrole on the AISI $316 \mathrm{~L}$ grade stainless steel substrate initiated fast as evidenced by the sharp increase in the anodic current density. The recorded current density was high, e.g. tens of milliamperes, compared to typical values of several milliamperes reported in the literature ${ }^{1-6}$ due to the reasonably high solubility of pyrrole monomer in methanesulphonic acid, enabling reactant concentrations from 0.01 to $1.0 \mathrm{~mol} \mathrm{dm}^{-3}$. At the highest monomer concentration, a single peak was observed at $+1.2 \mathrm{~V}(\mathrm{SCE})$ due to the oxidation of pyrrole to polypyrrole. At lower concentrations of pyrrole the peak became less defined and the

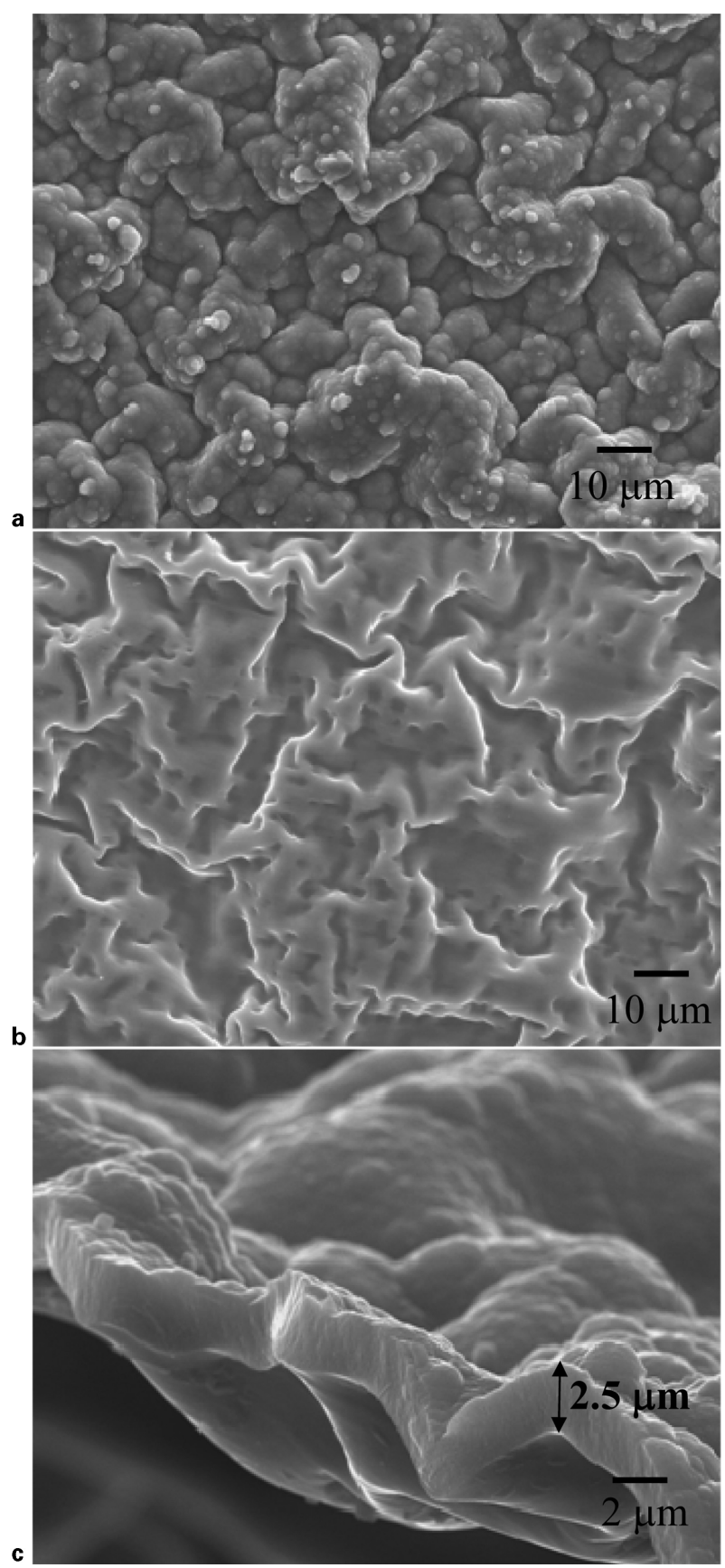

4 Surface morphology of polypyrrole membrane: $a$ top surface; $b$ bottom surface and $c$ cross-sectional view. Polypyrrole film $(2.5 \mu \mathrm{m})$ was deposited from $0.01 \mathrm{~mol} \mathrm{dm}^{-3}$ pyrrole in $1.0 \mathrm{~mol} \mathrm{dm}^{-3}$ methanesulphonic acid at current density of $0.5 \mathrm{~mA} \mathrm{~cm}^{-2}$ for deposition time of $3600 \mathrm{~s}$ at electrolyte temperature of $295 \mathrm{~K}$

highest current point shifted to negative values as the monomer concentration increased. At a more positive potential than $+1.6 \mathrm{~V}(\mathrm{SCE})$ oxygen evolution additionally occurred on the surface of the polypyrrole film. The reduction of polypyrrole to pyrrole did not occur on the reverse potential sweep indicating an irreversible oxidation of pyrrole to polypyrrole.

\section{Effect of concentration of pyrrole on deposition of polypyrrole}

Figure 2B shows the effect of pyrrole concentration on the cyclic voltammograms. As expected, when a higher concentration of pyrrole was used, the anodic peak current 


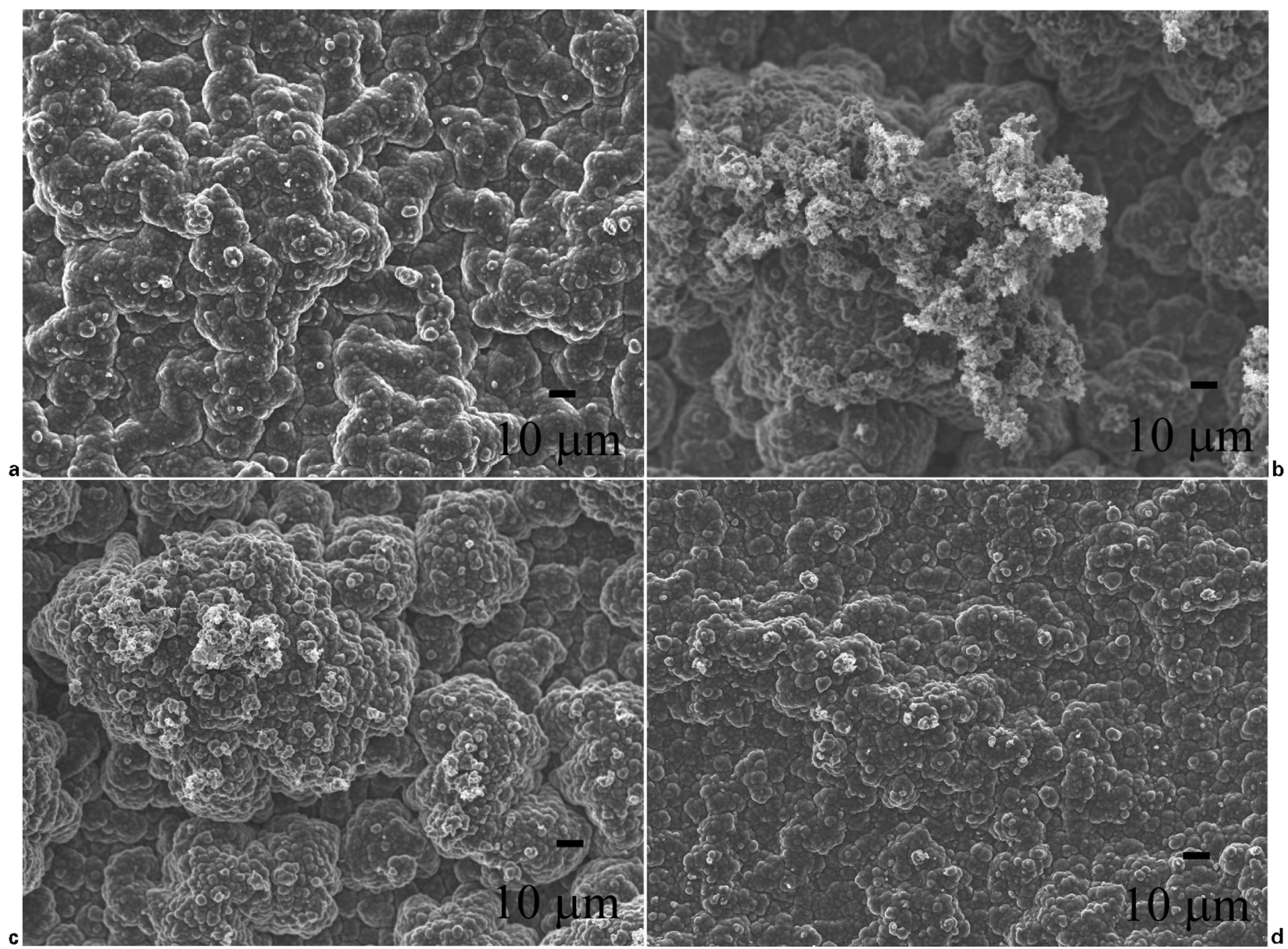

5 Scanning electron micrograph images of top surface of polypyrrole films showing effect of pyrrole concentration and methanesulphonic acid concentration on deposit morphology. Constant current density deposition for 60 min at $1 \mathrm{~mA} \mathrm{~cm}^{-2}$ from electrolytes containing: a $0.01 \mathrm{~mol} \mathrm{dm}^{-3}$ pyrrole $+0.5 \mathrm{~mol} \mathrm{dm}^{-3}$ methanesulphonic acid; $b$ $0.6 \mathrm{~mol} \mathrm{dm}^{-3}$ pyrrole $+0.5 \mathrm{~mol} \mathrm{dm}^{-3}$ methanesulphonic acid; $c \quad 0.6 \mathrm{~mol} \mathrm{dm}^{-3}$ pyrrole $+1 \mathrm{~mol} \mathrm{dm}^{-3}$ methanesulphonic acid; $d 0.6 \mathrm{~mol} \mathrm{dm} \mathrm{dm}^{-3}$ pyrrole $+3 \mathrm{~mol} \mathrm{dm}^{-3}$ methanesulphonic acid

density increased and could reach several hundred miliamperes. The anodic peak current density, $j_{\mathrm{p}}$ increased linearly with concentration of pyrrole, $c$ as shown in Fig. 2B. This linear relationship indicates complete diffusion control and follows the Randles-Sevćik equation ${ }^{19}$

$$
j_{\mathrm{p}}=\left(2.69 \times 10^{5}\right) n^{1.5} D^{0.5} c v^{0.5}
$$

Assuming reaction (1) to progress via an $n=2.25$ electron loss per monomer unit, ${ }^{17,20} c$ is the pyrrole monomer concentration and $v$ is the kinematic viscosity of the electrolyte. Using the value of the slope from Fig. $2 \mathrm{~B}, \mathrm{~d}\left(j_{\mathrm{p}}\right) / \mathrm{d} c$, the diffusion coefficient of pyrrole in methanesulphonic acid, $D$ was estimated to be approximately $1.4 \pm 0.2 \times 10^{-6} \mathrm{~cm}^{2} \mathrm{~s}^{-1}$. This is in agreement with typical values of $1.3 \pm 0.15 \times 10^{-5}$ (Ref. 18) or $1.25 \pm 0.1 \times 10^{-5} \mathrm{~cm}^{2} \mathrm{~s}^{-1}$ found in the literature. ${ }^{21}$

\section{Effect of methanesulphonic acid concentration on polypyrrole deposition}

Figure 3 shows the effect of methanesulphonic acid concentration on the cyclic voltammetry. The charge involved in the anodic deposition of polypyrrole was estimated from the area under the curve.

\section{Surface microstructure and cross-sectional imaging of polypyrrole film}

The as deposited polypyrrole film was black in colour. Figure $4 a-c$ shows scanning electron micrographs of an as deposited polypyrrole film. The surface of the film, which is in contact with the electrolyte appeared roughened, compact and non-dendritic. The surface in contact with the stainless steel substrate showed a finer microstructure compared to the top surface. At the initial stage of deposition, the growth of polypyrrole film followed the surface profile of the substrate. At a later stage, the film continued to grow but followed the surface profile of the deposited film. As a result, the surface microstructure became rougher as the polypyrrole film grew. This finding was similar to typical observations during the electrodeposition of metals from aqueous electrolytes.

Polypyrrole films deposited at current densities as low as $1 \mathrm{~mA} \mathrm{~cm}{ }^{-2}$ showed a compact finish while films deposited at higher current densities, e.g. $>10 \mathrm{~mA} \mathrm{~cm}^{-2}$ showed an irregular, nodular surface finish. The polypyrrole films could also be deposited at a constant potential or incremental (staircase) current density to produce thick, flexible film. The films produced by such 


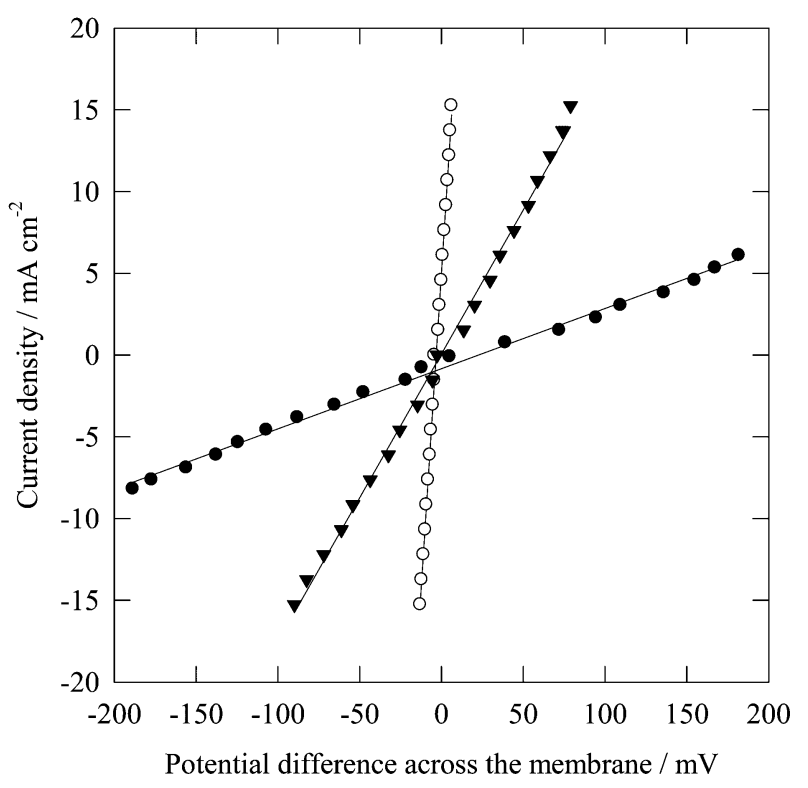

6 Current density versus electrode potential across freely-standing polypyrrole membrane in $1.0 \mathrm{~mol} \mathrm{dm}^{-3}$ methanesulphonic acid at $295 \mathrm{~K}$. About $9 \mu \mathrm{m}$ thick polypyrrole film was deposited from $0.01 \mathrm{~mol} \mathrm{dm}^{-3}$ pyrrole in electrolyte containing $\bullet 1.0 \mathrm{~mol} \mathrm{dm}^{-3}$ methanesulphonic acid or $\nabla 4.0 \mathrm{~mol} \mathrm{dm}{ }^{-3}$ methanesulphonic acid at current density of $1 \mathrm{~mA} \mathrm{~cm}{ }^{-2}$ for deposition time of $3600 \mathrm{~s}$. $\bigcirc$ is response in absence of polypyrrole membrane

methods showed a compact surface microstructure. The scanning electron micrographs of Fig. 5 show the effect of $a, b$ pyrrole concentration and $b, c$ and $d$ methanesulphonic acid concentration on the film morphology during constant current density deposition for $60 \mathrm{~min}$ at $1 \mathrm{~mA} \mathrm{~cm}{ }^{-2}$ from electrolytes containing: $a 0.01 \mathrm{~mol} \mathrm{dm}^{-3}$ pyrrole $+0.5 \mathrm{~mol} \mathrm{dm}{ }^{-3}$ methanesulphonic acid; $b 0.6 \mathrm{~mol}$ $\mathrm{dm}^{-3}$ pyrrole $+0.5 \mathrm{~mol} \mathrm{dm}{ }^{-3}$ methanesulphonic acid; $c$ $0.6 \mathrm{~mol} \mathrm{dm}{ }^{-3}$ pyrrole $+1 \mathrm{~mol} \mathrm{dm}^{-3}$ methanesulphonic acid,

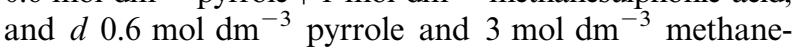
sulphonic acid. More compact, less porous films were produced at a higher concentration of methanesulphonic acid and a lower concentration of the pyrrole monomer.

\section{Electrolytic resistivity of freely-standing polypyrrole films}

Figure 6 shows a plot of current density flowing versus electrode potential across a freely-standing polypyrrole film. The average resistance of the membrane was estimated from the linear slope of the curve. ${ }^{18,21}$ It showed that a polypyrrole film prepared in $4.0 \mathrm{~mol} \mathrm{dm}^{-3}$ methanesulphonic had a lower resistance as compared to a film prepared in $1.0 \mathrm{~mol} \mathrm{dm}{ }^{-3}$ methanesulphonic acid. In Table 1, the estimated membrane area resistance was shown for freely-standing polypyrrole films deposited over a range of controlled conditions. The concentration of methanesulphonic acid and charge density was found to have a more pronounced influence on the membrane area resistance of the polypyrrole film. The most conductive membrane was achieved at higher concentrations of methanesulphonic acid and at a lower deposition charge density. The values of area resistance of the present methanesulphonate doped films in the oxidised state are comparable to those of polypyrrole films doped with tetrafluoroborate anions. ${ }^{18,22}$

Karambelkar et $a l^{23}$ have reported chemical synthesis of pyrrole from methanesulphonic acid dopant using persulphate oxidation of the monomer in an inverted microemulsion using a surfactant-chloroform-acetone solvent. A short reaction time of $70 \mathrm{~min}$ and a yield of over $83 \%$ weight were reported at $20^{\circ} \mathrm{C}$. While this is a means of synthesising the pyrrole salt as bulk amorphous powder of mean particle size $4.4 \mu \mathrm{m}$, rather than a controlled surface film of polypyrrole, it is interesting to note the use of the methanesulphonate dopant. As in the case of reaction (1), the mechanism of pyrrole synthesis was considered to involve a pyrrole radical cation.

\section{Porous, three-dimensional layers at high positive potentials}

This study was largely aimed at the deposition of freelystanding, compact films of polypyrrole having controlled thickness at moderate electrode potentials and

Table 1 Membrane area resistance of freely-standing polypyrrole films in $1.0 \mathrm{~mol} \mathrm{dm}^{-3}$ methanesulphonic acid*

Operating parameters used

to prepare polypyrrole thin films

from methanesulphonic acid
Membrane area resistance of freely-standing polypyrrole thin film/ohm $\mathrm{cm}^{2}$

\begin{tabular}{ll}
\hline Concentration of methanesulphonic acid $/ \mathrm{mol} \mathrm{dm}$ & \\
1.0 & 42 \\
2.0 & 35 \\
4.0 & 10 \\
Concentration of pyrrole/mol dm & \\
0.01 & 90 \\
0.5 & 90 \\
1.0 & 95 \\
Applied current density/mA cm & -2 \\
0.5 & \\
1.0 & 47 \\
2.0 & 42 \\
Deposition time/s & 42 \\
30 & \\
120 & 21 \\
240 & 52 \\
\end{tabular}

*Unless stated, the polypyrrole film was anodically electrodeposited onto stainless steel substrate from $0.01 \mathrm{~mol}^{\mathrm{dm}}{ }^{-3}$ pyrrole in $1.0 \mathrm{~mol} \mathrm{dm}{ }^{-3}$ methanesulphonic acid at current density of $1 \mathrm{~mA} \mathrm{~cm}{ }^{-2}$ over deposition time: of $3600 \mathrm{~s}$ at electrolyte temperature of $295 \mathrm{~K}$. 


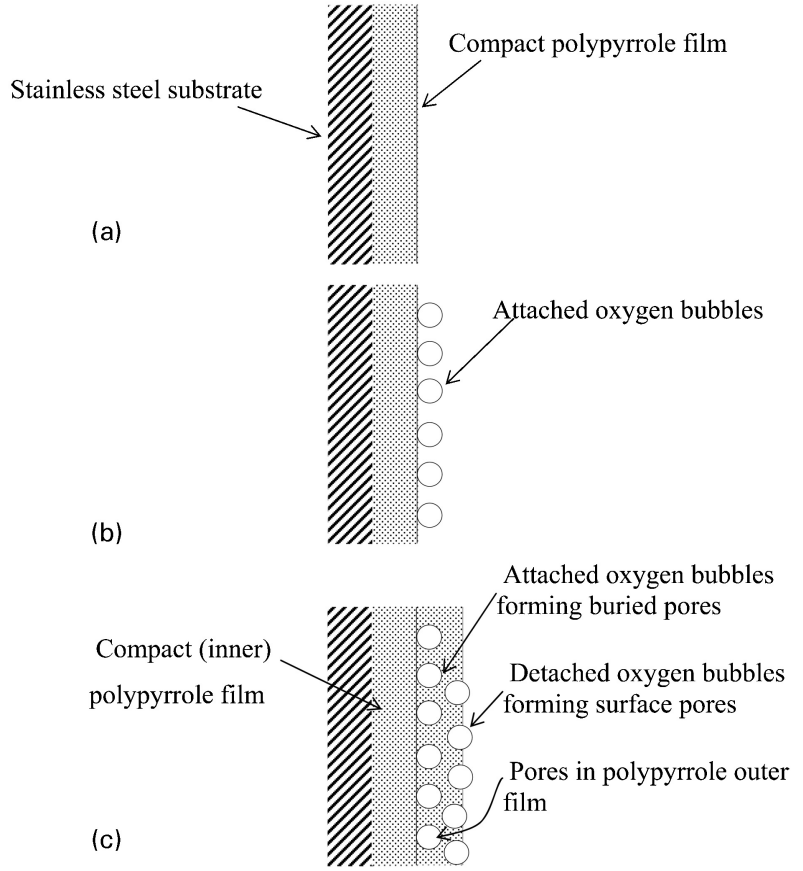

a deposition of thin, compact polypyrrole film; $b$ generation of $\mathrm{O}_{2}$ bubbles on top surface of film via secondary reaction beginning to evolve at polymer surface; $c$ continuation of anodic polymer deposition and growth on existing film and around bubbles forming microporous layer

7 Principle of anodically forming porous polypyrrole film using templating by evolved oxygen bubbles using three-step sequence

current densities. During the study, it was also found possible to deposit detachable and swollen polymer films having marked porosity via the evolution of oxygen at the surface of the polypyrrole film at potentials more positive than $+1.6 \mathrm{~V}(\mathrm{SCE})$ via reaction (2), typically at current densities of $1-10 \mathrm{~mA} \mathrm{~cm}{ }^{-2}$.

This is effectively a template-less deposition of polymer due to gas bubble voidage, the principles being indicated in Fig. 7. The realisation of thick $(1-10 \mathrm{~mm})$, highly flexible and free-standing polypyrrole film, having a random, micropore structure, on a polished stainless steel substrate using this technique is illustrated in Fig. 8. The most reproducible conditions used a three-step sequence:

(i) anodic deposition of a thin, compact polypyrrole film

(ii) moderate anodic generation of $\mathrm{O}_{2}$ bubbles on the top surface of the film

(iii) continued polymer deposition on the existing film around the bubbles.

The gas bubble induced templating of porosity deserves further study, particularly its control via bubble size. Other examples of 'template-free' deposition of porous metal, ${ }^{24}$ metal oxide ${ }^{25}$ and polymer layers ${ }^{26-28}$ under different operational conditions have been considered as have general methods for template synthesis of conjugated polymers. ${ }^{28}$ Such films may find applications as speciality membranes or electrodes in batteries or supercapacitors.

\section{Conclusions}

1. Electrically conducting polypyrrole films were anodically deposited onto a mirror-finish stainless steel substrate from aqueous methanesulphonic acid. A wide

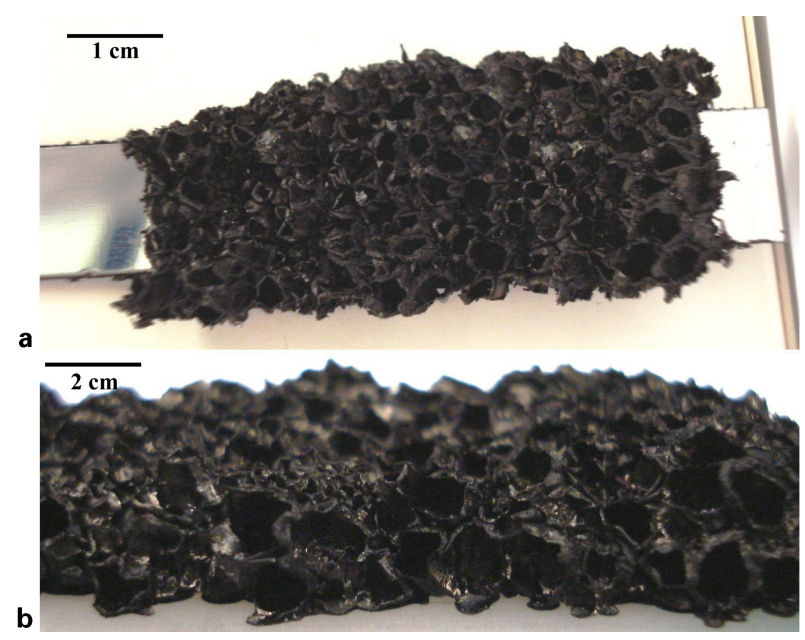

a growth of porous polypyrrole film on electrode; $b$ detached polymer film at longer times

8 Formation of thick $(>10 \mathrm{~mm}$ ) highly flexible, porous, 3D polypyrrole films during extended anodic deposition from $0.1 \mathrm{~mol} \mathrm{dm}^{-3}$ pyrrole $+0.5 \mathrm{~mol} \mathrm{dm}^{-3}$ methanesulphonic acid at $295 \mathrm{~K}$, using constant current density of 1 to $10 \mathrm{~mA} \mathrm{~cm}^{-2}$ in presence of oxygen evolution as secondary reaction. Electrolyte was continuously stirred by magnetic follower at $300 \mathrm{rev} \mathrm{min}^{-1}$

range of electrolyte compositions can be used including 0.01 to $1.0 \mathrm{~mol} \mathrm{dm}^{-3}$ pyrrole in 1.0 to $6.0 \mathrm{~mol} \mathrm{dm}^{-3}$ methanesulphonic acid at $295 \mathrm{~K}$.

2. The oxidised polypyrrole films were readily doped with methanesulphonate anion during polymerisation. Compact and non-dendritic films up to $100 \mu \mathrm{m}$ thick were produced at a low deposition current density $\left(<1 \mathrm{~mA} \mathrm{~cm}^{-2}\right)$ in an electrolyte containing a low concentration of pyrrole $\left(0.1 \mathrm{~mol} \mathrm{dm}^{-3}\right)$ and a high concentration of methanesulphonic acid $\left(6 \mathrm{~mol} \mathrm{dm}{ }^{-3}\right)$.

3 . Freely-standing polypyrrole films of $10 \mu \mathrm{m}$ thickness showed membrane area resistances of 10 $95 \mathrm{ohm} \mathrm{cm} \mathrm{cm}^{2}$ in $1 \mathrm{~mol} \mathrm{dm}^{-3}$ methanesulphonic acid at $295 \mathrm{~K}$. The membrane ionic conductivity was dependent on the reaction environment (current density, deposition time, pyrrole level and methanesulphonic acid concentration). The most conductive membranes were achieved in a high concentration of methanesulphonic acid $\left(6 \mathrm{~mol} \mathrm{dm}^{-3}\right)$ at a low deposition current density $\left(0.2 \mathrm{~mA} \mathrm{~cm}^{-2}\right)$.

4. Porous, swollen polymer films were achieved at high current densities in the presence of oxygen evolution as a secondary reaction and deserve further attention due to the possibility of steering pore shape and size by selection of electrolyte composition and control of electrode potential or current density.

\section{Acknowledgements}

The authors are grateful to the financial support provided to V. Caramia by the LLP/Erasmus Student Placement Programme 2008-2009. This work formed part of V.C.'s final year undergraduate project in Laurea Specialistica in Ingegneria Aerospaziale ed Astronautica at the University of Salento, Italy. Thanks are due to Professor B. Bozzini, University of Salento, Lecce, for helpful comments and colleagueship. The authors thank L. F. Arenas for assistance with the drawing of Fig. 1. 


\section{References}

1. G. G. Wallace, G. M. Spinks, L. A. P. Kane-Maguire and P. R. Teasdale: 'Conductive electroactive polymers intelligent polymer systems', 2nd edn; 2002, Boca Raton, FL, CRC Press.

2. S. A. Campbell, J. R. Smith, Y. Li, S. Breakspear and F. C. Walsh: 'Conducting polymer coatings in electrochemical technology Part 1 - Synthesis and fundamental aspects', Trans. IMF, 2007, 85, 237244.

3. S. A. Campbell, J. R. Smith, Y. Li, S. Breakspear and F. C. Walsh: 'Conducting polymer coatings in electrochemical technology. Part 2 - Application areas', Trans. IMF, 2008, 85, 34-40.

4. P. Chandrasekhar: 'Conducting polymers: fundamentals and applications. a practical approach'; 1999, Dordrecht, Kluwer Academic.

5. R. B. Kaner: in 'Electrochemical science and technology of polymers', (ed. R. G. Linford), 97; 1990, Essex, Elsevier Applied Science.

6. L. E. A. Berlouis and D. J. Schiffrin: 'Recent advances in electrochemical polymerisation for surface coating', Trans. IMF, 1986, 64, 42-46.

7. J. R. Smith, Y. Li, S. Breakspear, D. Whiteley, P. A. Cox, S. A. Campbell and F. C. Walsh: 'Electrochemical and computational studies of electrically conducting polymer coatings', Trans. IMF, 2011, 89, 244-248.

8. B. Kim, P. Innis, G. G. Wallace, C. T. J. Low and F. C. Walsh: 'Electrically conductive coatings of nickel and polypyrrole/poly(2methoxyaniline-5-sulphonic acid) on nylon lycra textiles', Prog. Org. Coat., 2013, 76, 1296-1301.

9. K. Jurewicz, S. Delpeux, V. Bertagna, F. Beguin and E. Frackowiak: 'Supercapacitors from nanotubes/polypyrrole composites', Chem. Phys. Lett., 2010, 347, 36-40.

10. B. Grunden and J. O. Itoh: 'Formation of graphite fibrepolypyrrole coatings by aqueous electrochemical polymerization', Polymer, 1995, 36, 559-583.

11. S. W. Feldberg: 'Reinterpretation of polypyrrole electrochemistry. Consideration of capacitive currents in redox switching of conducting polymers', J. Am. Chem. Soc., 1984, 106, 4671-4674.

12. M. D. Gernon, M. Wu, T. Buszta and P. Janney: 'Environmenta benefits of methanesulphonic acid. Comparative properties and advantages', Green Chem., 1999, 1, 127-140.

13. C. T. J. Low and F. C. Walsh: 'The influence of a perfluorinated cationic surfactant on the electrodeposition of tin from a methanesulphonic acid bath', J. Electroanal. Chem., 2008, 615, 91-102.

14. C. T. J. Low and F. C. Walsh: 'Normal and anomalous electrodeposition of tin-copper alloys from methanesulphonic acid bath containing perfluorinated cationic surfactant', Trans. IMF, 2008, 86, 315-325.
15. C. T. J. Low, M. de la Toba Corral and F. C. Walsh: 'Anodising of titanium in methanesulphonic acid to form titanium dioxide nanotube arrays', Trans. IMF, 2011, 89, 44-50.

16. I. Sirés, C. T. J. Low, C. Ponce de Len and F. C. Walsh: 'The deposition of nanostructured $\beta-\mathrm{PbO}_{2}$ coatings from aqueous methanesulphonic acid for the electrochemical oxidation of organic pollutants', Electrochem. Commun., 2010, 12, 70-74.

17. Y. Shen and M. Wan: 'Soluble conductive polypyrrole synthesized by in situ doping with $\beta$-naphthalene sulphonic acid', J. Polym. Sci. Part A: Polym. Chem., 1997, 35, 3689-3695.

18. J. Tietje-Girault, C. Ponce de Leon and F. C. Walsh: 'Electrochemically deposited polypyrrole films and their characterization', Surf. Coat. Technol., 2007, 201, 6025-6034.

19. D. Pletcher: 'A first course in electrode processes', 2nd edn; 2009, Cambridge, Royal Society of Chemistry.

20. S. Slade, S. A. Campbell, T. R. Ralph and F. C. Walsh: 'Ionic conductivity of an extruded Nafion 1100 EW series of membranes', J. Electrochem. Soc., 2002, 149, A1556-A1564.

21. Q. Fulian and R. G. Compton: 'Laser-activated voltammetry: measurement of the diffusion coefficients of electropassivating species. application to pyrrole and phenol in aqueous solution', Anal. Chem., 2000, 72, 1830-1834.

22. A. F. Diaz and J. J. Castillo: 'A polymer electrode with variable conductivity: polypyrrole', J. Chem. Soc. Chem. Commun., 1980, (9), 397-402.

23. V. V. Karambelkar, J. D. Ekhe and S. N. Paul: 'High yield polypyrrole: A novel approach to synthesis and characterization', J. Mater. Sci., 2011, 4, 5324-5331.

24. G. M. Yang, X. Chen, J. Li, Z. Guo and J. H. Liu: 'Bubble dynamic templated deposition of three-dimensional palladium nanostructure catalysts: Approach to oxygen reduction using macro-, micro-, and nano-architectures on electrode surfaces', Electrochim. Acta, 2011, 56, 6771-6778.

25. J. Yang, H. Huang, Q. Lin, L. Lu, X. Chen, L. Yang, X. Zhu, Z. Fan, Y. Song and D. Li: 'Morphology defects guided pore initiation during the formation of porous anodic alumina', Appl. Mater. Interfaces, 2014, 6, 2285-2291.

26. F. Hui, B. Li, P. He, J. Hub and Y. Fang: 'Electrochemical fabrication of nanoporous polypyrrole film on HOPG using nanobubbles as templates', Electrochem. Commun., 2009, 11, 639642.

27. L. Qu, G. Shi, J. Yuan, G. Han and F. Chen: 'Preparation of polypyrrole microstructures by direct electrochemical oxidation of pyrrole in an aqueous solution of camphorsulphonic acid', $J$. Electroanal. Chem., 2004, 561, 149-156.

28. M. Mazur and P. Krysiński: 'Electrochemical template synthesis of conjugated polymers', Curr. Top. Electrochem., 2007, 12, 15-31. 